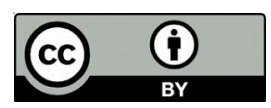

UDC 81'25:070.432

LBC 81.18
Submitted: 09.11.2020

Accepted: 30.03 .2021

\title{
TRANSLATION OF ANALYTICAL ARTICLES FOR MASS MEDIA: PRAGMATICS OF DISCOURSES ${ }^{1}$
}

\author{
Vera A. Mityagina \\ Volgograd State University, Volgograd, Russia \\ Yuliya V. Chemeteva \\ Volgograd State University, Volgograd, Russia
}

\begin{abstract}
The paper examines the features of analytical articles in the mass media, which appear due to the interaction of different discourses that form a specific genre of media analytics. Using the material of original analytical articles written in English and German, and their published translations, the authors investigate manifestations of such characteristics as hybridity, diffuseness, intertextuality, as well as translation problems that arise during translation. Based on the analysis of scientific works on the issues of genre hybridity and diffuseness in media discourse, the authors clarify the ambiguous interpretation of the concept of diffuseness and define its boundaries with the concept of hybridity. The research also reveals the following forms of intertextuality caused by the interaction of discourses within the genre of analytical article on legal issues: reference to another text in the form of a hyperlink, citation, allusion. The analysis of fragments from analytical articles of media discourse containing manifestations of hybridity, diffuseness, and intertextuality demonstrates that a translator who is dealing with a text with these characteristics should excellently know the terminology of the basic and projective discourse in the original and target language, be aware of the neologization processes in both discourses, master stylistic transformations, and take into account the pragmatic factors caused by the interaction of the discourses.

Key words: media discourse, media analytics, translation, pragmatics, hybridity, diffuseness, intertextuality.

Citation. Mityagina V.A., Chemeteva Yu.V. Translation of Analytical Articles for Mass Media: Pragmatics of Discourses. Vestnik Volgogradskogo gosudarstvennogo universiteta. Seriya 2. Yazykoznanie [Science Journal of Volgograd State University. Linguistics], 2021, vol. 20, no. 3, pp. 29-44. (in Russian). DOI: https://doi.org/10.15688/jvolsu2.2021.3.3
\end{abstract}

УДК $81 ’ 25: 070.432$

Дата поступления статьи: 09.11.2020

ББК 81.18 Дата принятия статьи: 30.03.2021

\section{ПЕРЕВОД АНАЛИТИЧЕСКОЙ СТАТЬИ ДЛЯ МАССМЕДИА:} ПРАГМАТИКА ДИСКУРСОВ ${ }^{1}$

\author{
Вера Александровна Митягина \\ Волгоградский государственный университет, г. Волгоград, Россия \\ Юлия Владимировна Чеметева \\ Волгоградский государственный университет, г. Волгоград, Россия
}

Аннотация. В работе рассматриваются особенности аналитических статей в медийном дискурсе, обусловленные взаимодействием разных дискурсов, образующих конкретный жанр медийной аналитики. На материале оригинальных англоязычных и немецкоязычных статей и их опубликованных переводов исследуется проявление таких характеристик этих текстов, как гибридность, диффузность, интертекстуальность. Описаны переводческие проблемы, возникающие в ходе передачи языковых средств, выражающих данные характеристики. 
На основе анализа научных работ по вопросам жанровой гибридности и диффузности в медийном дискурсе авторами уточняется неоднозначная до настоящего времени трактовка понятия диффузности, определяются его границы и признаки, отличающие его от понятия гибридности. Выявлены формы интертекстуальности, обусловленные взаимодействием дискурсов в рамках жанра аналитической статьи по юриспруденции: отсылка к другому тексту, оформленная как гиперссылка, цитирование, аллюзия. Результаты анализа фрагментов из аналитических статей медийного дискурса, в которых проявляются гибридность, диффузность, интертекстуальность, демонстрируют, что переводчику, осуществляющему перевод текста с указанными характеристиками, необходимо на высоком уровне владеть терминологией базового и проективного дискурсов на языке оригинала и языке перевода, быть осведомленным о процессах неологизации в обоих дискурсах, владеть техникой стилистических преобразований и учитывать прагматические факторы, обусловленные взаимодействием дискурсов.

Ключевые слова: медийный дискурс, медийная аналитика, перевод, прагматика, гибридность, диффузность, интертекстуальность.

Цитирование. Митягина В. А., Чеметева Ю. В. Перевод аналитической статьи для массмедиа: прагматика дискурсов // Вестник Волгоградского государственного университета. Серия 2, Языкознание. - 2021. T. 20, № 3. - C. 29-44. - DOI: https://doi.org/10.15688/jvolsu2.2021.3.3

\section{Введение}

Современные вызовы, с которыми сталкивается общество, носят комплексный характер и требуют принятия взвешенных, решительных мер, что обусловливает растущую роль аналитической составляющей в процессе обработки данных и принятия управленческих решений. Без аналитики в настоящее время невозможно представить управление бизнесом, какой-либо отраслью, государством. Выстраивание стратегии, выбор методов решения задач осуществляется с привлечением аналитических данных, получение которых требует высокой концентрации интеллекта. Немаловажной является способность каждого гражданина, не вовлеченного в аналитическую деятельность высокого уровня, мыслить аналитически, осознавать процессы, протекающие в организации, где он работает, государстве, гражданином которого является. На развитие интеллектуального потенциала населения оказывает влияние потребляемая им информация, значительную часть которой граждане получают из аналитических текстов медийного дискурса, в котором затрагиваются вопросы юриспруденции, политики, экономики, экологии и т. д. По мнению В.Б. Исакова, такие тексты способствуют развитию аналитического мышления населения, влияют на общественное сознание, представления граждан о протекающих в государстве процессах, а также на формирование их гражданской позиции при участии в отправлении демократии [Исаков, 2018, с. 117].
Уступая информационным жанрам в простоте изложения материала, аналитические жанры, тем не менее, в целом соответствуют параметрам, задаваемым медийным дискурсом, и поддерживают новые форматы, адаптируясь к актуальным тенденциям. Сложность восприятия текста в жанрах медийной аналитики обусловливается фокусом на предметности, которая определяется принадлежностью того или иного текста к какому-либо специализированному дискурсу (юридическому, научному, политическому, медицинскому, экономическому и т. д.). Однако ведущая роль медийного дискурса как базового, универсального в рамках жанров медийной аналитики определяет множество их прагматических характеристик. В результате взаимодействия дискурсов актуализируются такие жанровые характеристики, как диффузность, гибридность, интертекстуальность. Однако при переводе аналитических текстов медийного дискурса не всегда учитывается природа данных характеристик, а также прагматические факторы, заложенные в них и обусловленные взаимодействием базового и проективного дискурсов.

Эвристичной является высказанная немецкими исследователями М. Хайнеман и В. Хайнеманом мысль о «дискурсивном знании» (Diskurswissen) [Heinemann M., Heinemann W., 2002, S. 181], которое должно стать основой выбора для текста перевода адекватных структурных и языковых средств, равноценных тем, которые использовал автор. Это знание актуализируется у переводчика в процессе анализа 
B.A. Митягина, Ю.В. Чеметева. Перевод аналитической статьи для массмедиа: прагматика дискурсов

переводческого заказа, в котором выявляются такие компоненты дискурсивной матрицы, как специфика текста, роли участников, время, место, цели, обстоятельства, стратегии. Анализируя данные компоненты, переводчик составляет переводческое досье для последующей межкультурной медиации, что позволяет активизировать мыслительную деятельность переводчика и способствует оптимизации его коммуникативного действия как культурного транслятора [Новикова, 2017б, с. 93].

Исследуемая проблема заключается в специфике взаимодействия дискурсов в рамках жанра аналитической статьи, обусловливающей проявление гибридности, диффузности, интертекстуальности. Работа нацелена на изучение указанных характеристик в прагматическом аспекте, уточнение границ понятия диффузности и анализ трудностей, возникающих при переводе аналитических публикаций.

\section{Методы и материал}

Эмпирическую базу исследования составляет массив из 30 текстов, полученный методом сплошной выборки аналитических статей правовой проблематики за 2014-2020 гг., представленных на официальных сайтах англоязычных и немецкоязычных изданий The Guardian, The Times, The Spectator, The New York Times, Frankfurter Allgemeine Zeitung и др., их переводы на русский язык, представленные на ресурсах InoPressa, ИноСМИ.ru, а также аналитические материалы онлайн платформы dekoder.org и мультимедийного проекта https://crimea.dekoder.org на немецком (dekoder.org: Russland entschlüsseln// https://www.dekoder.org/de) и русском (dekoder. org: Читая Европу//https://www.dekoder.org/ru) языках.

Исследование проводилось с использованием общенаучных методов индукции, обобщения, анализа, синтеза, описания и специализированных лингвистических методов контекстуального и дискурсивного анализа.

\section{Результаты и обсуждение}

\section{Гибридность в медийной аналитике}

Жанры медийной аналитики представляют собой продукт взаимодействия базового (медийного) и проективного (юридического, научного, политического, медицинского, экономического и т. д.) дискурсов, которое определяется такими терминами, как «гибридность», «диффузность». Иногда они используются учеными как взаимозаменяемые. Для более полного описания специфики взаимодействия дискурсов в рамках одного жанра рассмотрим понятие гибридности и диффузности в исследованиях зарубежных и российских лингвистов и переводчиков.

Понятие гибридности известно в рамках теории перевода, однако характеризуется оно по-разному. Некоторые исследователи отождествляют перевод и гибрид. Так, К. Шеффнер и Б. Адаб, полагая, что гибридные тексты являются следствием современной межкультурной коммуникации и образуются в результате контакта разных языков и культур, рассматривают его как результат перевода, содержащий необычные для принимающей культуры элементы [Schäffner, Adab, 2005, p. 169]. И. Зауберга говорит о том, что понятие гибридности выходит далеко за пределы перевода. Автор рассматривает гибридность как неизбежное следствие современной межкультурной коммуникации и полагает, что ее необходимо трактовать как естественный результат преодоления культурных барьеров [Zauberga, 2005, p. 266]. Ш. Саймон, М. СнеллХорнби, А. Пим высказывают мнение, что гибридность проявляется в смешении кодов, не обязательно являясь при этом переводом [Simon, 2005; Snell-Hornby, 2005; Pym, 2005]. Феномен гибридного текста, согласно М. Снелл-Хорнби, отражает реальность нашего сегодняшнего мира, который сам по себе является гибридным. Автор связывает природу гибридного текста с глобализацией, способствующей размыванию границ и преодолению географических барьеров [Snell-Hornby, 2005, p. 208]. Упомянутые трактовки так или иначе сводятся к представлению гибридности как наличию элементов чужеродных, неестественных для определенного дискурса.

В рамках исследования понятия гибридности применительно к жанрам значимыми являются работы А.А. Тертычного, в которых показано, что гибридные жанровые формы порождаются сочетанием исходных форм. Ученый отмечает, что «появляются 
гибридные жанры, служащие одновременно журналистике и пиару, идет мутация содержания жанровых форм журналистики, расширяется круг применения жанров западной журналистики» [Тертычный, 2013, с. 127]. O процессе «пересмотра» жанровых границ, их раздвижении, появлении новых жанров рассуждает Л.Е. Кройчик [Кройчик, 2014, c. 133]. Согласно Е.Г. Малышевой и Н.А. Гридневу, гибриды представляют собой специфические тексты, жанровая принадлежность которых неоднозначна в силу наличия в них признаков различных жанров [Малышева, Гриднев, 2015, с. 111].

Ученые выделяют в рамках гибридности различные уровни [Кисткина, 2017, с. 6063; Новикова, 2017а, с. 97], типы [Хотног, 2019, c. 191]. Проблеме гибридности был посвящен Десятый съезд Российского союза германистов, где был рассмотрен широкий круг вопросов, затрагивающих данную категорию (обзор см.: [Быкова, 2013]).

Гибридность аналитической статьи в массмедиа обусловлена взаимодействием реализуемых ею информативной и апеллятивной функций. В этой связи универсальность вывода, который сделал А.Г. Пастухов на немецкоязычном материале: немецкоязычные аналитические тексты ориентированы на трансляцию мнения и представлены как «meinungsbetonte Formen (формы, ориентированные на мнение), MeinungsDarstellungsformen (мнениеформирующие формы), meinungsorientierte Darstellungsformen (мнениеориентирующие формы), Meinungsstilform (стилевые формы мнения), Meinungsbeiträge (мнениеформирующие статьи), meinungsäußernde/ kommentierende Darstellungsformen (мнениекомментирующие формы), kommentierende Stilformen (комментирующие стилевые формы) [Пастухов, 2020, с. 1111]. В работах С.С. Борисовой установлены персуазивные стратегии в немецкоязычных аналитических медиажанрах и доказано, что «наиболее частотным способом убеждения является рациональный способ информационного доминирования, второе место занимает эмоциональный, и наименее частотный, но также присутствующий в каждом медиатексте ценностный способ информационного доминирования» [Борисова, 2015, с. 114].
Согласно С. Тиркконен-Кондит, развитие новых типов и жанров текстов порождает межкультурная коммуникация, и отдельные стадии этого развития можно охарактеризовать как гибридизацию. Речь идет о тех стадиях, на которых новые типы и жанры текстов еще не вполне утвердились как формы коммуникации в социокультурной среде: в них проявляются языковые особенности, которые ощущаются как чужеродные. Ученый отмечает также, что концепция гибрида полезна в качестве инструмента описания переходных стадий, в рамках которых взаимодействуют и сосуществуют конфликтующие дискурсивные нормы [Tirkkonen-Condit, 2001, p. 264]. На данной переходной стадии, стадии гибрида, согласно логике концепции С. ТиркконенКондит, в жанре проявляются различные особенности, характерные для разных дискурсов. Автор обозначает такие особенности как конфликтующие, следовательно, на стадии гибрида, согласно данной концепции, происходит сочетание характеристик, присущих разным дискурсам или жанрам, а не их слияние, в результате которого появляется новая характеристика.

Помимо межкультурной коммуникации, факторами возникновения гибридности выступают развитие современных коммуникативных форм [Митягина, 2015, с. 290], развитие технологий и так называемое клиповое сознание массового реципиента [Градюшко, 2015, c. 156], полидискурсивность [Букеева, 2014, c. 58]. Важнейшую роль в раскрытии потенциала гибридных жанровых форм играют социальные медиа [Градюшко, 2015, с. 157], что делает медийные тексты наиболее актуальным материалом для исследования проблем гибридности. Рассмотрим пример проявления гибридности в жанре аналитической статьи по юриспруденции.

(1) Mr. Trump may very well choose to pardon not just his family and friends before leaving office but also himself in order to avoid federal criminal liability. This historic turn of events would have no effect on his potential criminal exposure at the state level. If Mr. Trump bestows such pardons, states like New York should take up the mantle to see that the rule of law is upheld. And pardons would not preclude the new attorney general challenging a self-pardon or the state calling the pardoned friends and family before the grand jury 
to advance its investigation of Mr. Trump after he leaves office (where, if they lied, they would still risk charges of perjury and obstruction).

In short, being president should mean you are more accountable, not less, to the rule of law (Weissmann A.).

Чтобы избежать федеральной уголовной ответственности, Трамп вполне может решить помиловать не только свою семью и друзей перед уходом с должности, но и себя самого, - считает Вайсман. - (...) Если Трамп дарует эти помилования, такие штаты, как Нью-Йорк, должны принять на себя ответственность и обеспечить соблюдение верховенства закона. И помилование не должно помешать новому генеральному прокурору оспорить самопомилование, а штату - вызвать помилованных друзей и родственников предстать перед большим жюри для содействия расследованию в отношении Трампа после того, как он уйдет с поста (где, если они солгут, они все равно рискуют получить обвинения в лжесвидетельстве и препятствовании).

«Короче говоря, быть президентом должно означать, что вы больше, а не меньше подотчетны верховенству закона», - заключает автор публикации (InoPressa).

При большой концентрации юридических терминов и официально-деловой лексики (federal criminal liability, criminal exposure, rule of law, attorney general, perjury и т. д.), что обусловлено предметностью текста, фрагмент содержит лексические единицы, чуждые юридическому дискурсу, однако допустимые в медийном дискурсе (take up the mantle, in short). В переводе данного фрагмента, представленном на сайте InoPressa, идиома take up the mantle передана как «принять на себя ответственность». При переводе метафорический компонент не воспроизводится, и словосочетание обретает стилистическую нейтральность. Передача компонента in short разговорным словосочетанием короче говоря усиливает в тексте перевода эффект гибридизации.

Аналитическое осмысление проблем международного права, в частности, «аннексии» Крыма в 2014 г., осуществляется в медийном формате, например:

(2) Der Völkerrechtsexperte Stefan Talmon sprach 2014 in einem Artikel für die FAZ von einer „Pflicht zum Ärgern” Russlands. Es bedürfe einer aktiven Nichtanerkennung des Status der Krim, um der, nach seiner Einschätzung, widerrechtlichen
Annexion zu begegnen. Andererseits besagt ein humanitärer politischer Grundsatz, dass die Zivilbevölkerung eines annektierten Gebiets nicht zusätzlichem Leid durch internationale Maßnahmen ausgesetzt werden sollte, etwa durch Verhängung von Sanktionen, von denen dieses Territorium betroffen wäre (Die Krim - ist das Völkerrecht...).

Юрист-международник Штефан Талмон в статье 2014 года, опубликованной в немецкой газете Frankfurter Allgemeine Zeitung, говорил о «моральной обязанности досаждать России» и указывал на необходимость активного непризнания статуса Крыма, считая данный случай незаконной аннексией со стороны России. И все же существует гуманитарный политический принцип, согласно которому гражданское население аннексированных земель не должно испытывать дополнительные страдания в связи с международными действиями, такими как санкции, оказывающие негативное влияние на их территорию (Пригодно ли международное право...).

В аналитическом мультимедийном досье (Das Multimedia-Dossier Archipel Krim // Мультимедийное досье «Архипелаг Крым») приводится цитата из статьи, написанной сразу после событий на Крымском полуострове, поэтому в материале имеет место несдержанность в оценке событий: в тексте используются несвойственные юридической аналитике, даже в ее массмедийном формате, оценочные номинации. Следует отметить, что уже название досье является аллюзией на «Архипелаг Гулаг» - полуостров Крым обозначен как архипелаг. Ссылка на статью профессора права Штефана Талмона (Talmon) и перевод ее названия Pflicht zum Ärgern как Моральная обязанность досаждать России отражают митигативное решение переводчика: апелляция Талмона к событиям в Китае (Манчжоу-Го), на Кипре, к коллективному опыту неприятия действия определенного государства эксплицирована в переводе прагматически неверно. Юрист призывает не досаждать, а злить, раздражать Россию. Данное решение переводчика и редактора мультимедийного проекта связано, видимо, со стремлением сохранить аналитическую доминанту статьи с помощью нейтральных лексических средств, не нарушающих сочетаемость ключевых номинаций.

Таким образом, гибридность жанра заключается в задействовании характерных для 
сопредельных дискурсов или жанров языковых средств, при котором не происходит их слияния в новую форму. В зависимости от совокупности жанровых и дискурсивных характеристик, а также характера взаимодействия базового и проективного дискурсов, гибридность может проявляться на различных уровнях и с разной степенью интенсивности, что должно учитываться при переводе текста.

\section{Диффузность в медийной аналитике}

Как было сказано ранее, феномен гибридности в исследованиях многих лингвистов тесно переплетается с диффузностью. Термин «диффузность» применительно к описанию размытости границ использовался в языкознании В.В. Химиком, Д.Н. Шмелевым, Б.Т. Ганеевым, которые исследовали семантическую размытость границ в рамках концептов. Согласно В.В. Химику, диффузными являются такие единицы плана выражения и плана содержания, которые отличаются «некоторыми нежесткими характеристиками и, в силу этого, неопределенностью, энтропией» [Химик, 2011, с. 717]. Д.Н. Шмелев, рассуждая о диффузности, говорит о размытости границ между значениями и отсутствии необходимости в обозначении границ, так как в большинстве случаев речь идет о новом смысле, который не соответствует в полной мере ни одному из значений в отдельности [Шмелев, 1990]. Б.Т. Ганеев рассматривает диффузность как источник энантиосемии, размытости границ употребления, расплывчатости содержания, его нечеткости [Ганеев, 2003, с. 13].

Применительно к жанрам понятие диффузности используется также в работах О.Ю. Багдасарян и С.А. Ереминой, В.А. Сулимова, С.В. Романовой, Ж.Р. Сладкевич [Багдасарян, Еремина, 2010; Сулимов, 2010; Романова, 2018; Сладкевич, 2016]. Материал медийного дискурса, как одного из наиболее динамично развивающихся, нагляден для представления диффузности жанров. Согласно Е.В. Войтишенюк, диффузность медиажанров представляет собой явление, «в результате которого тексты двух разных жанров объединяются в один и могут образовывать новые жанровые модели» [Войтишенюк, 2014, с. 55]. Это являет собой «совмещение нескольких жанров в одном тексте» [Войтишенюк, 2015, с. 192]; «процесс взаимодействия жанров, относящихся к разным типам дискурса» [Войтишенюк, 2015, с. 192]. Описывая данное явление, автор говорит о том, что новые (диффузные) модели появляются по мере запросов общества и способствуют обогащению языкового репертуара. Е.В. Войтишенюк, однако, не разграничивает понятия гибридизации и диффузности жанров, используя их как взаимозаменяемые.

В исследовании диффузности Л.И. Шевченко делает акцент на современных аналитических жанрах, отмечая, что аналитический текст «часто контрастирует с информационными вставками, “нарезками”, сюжетами, которые составляют одно коммуникационное поле» [Шевченко, 2014, с. 49-50]. Интернет-пространство выступает фактором, усиливающим диффузность жанра. Л.И. Шевченко говорит об аналитических медиажанрах как открытой системе, коррелирующей со временем и функциями массовой коммуникации, что обусловливает их лабильность, диффузность по структуре и языковым репрезентациям [Шевченко, 2014, с. 49-50]. Явление диффузности жанров в целом расценивается лингвистами как способствующее жанровому взаимообогащению.

Определяя причины диффузности, Л.Г. Флджян считает, что она является «объективным результатом усложняющихся отношений человека с окружающим миром, поскольку отражает изменения, происходящие в сознании человека» [Флджян, 2014]. А.А. Князев, рассуждая о постоянном обновлении жанров в журналистике, говорит о том, что наиболее активно данный процесс происходит в переходные моменты развития общества. Принимая во внимание ситуацию в мире, складывающуюся на фоне пандемии и активно освещаемую в медиатекстах, в том числе аналитических жанров, можно говорить об особой актуальности изучения переходных состояний жанров медийного дискурса, новых жанровых форм, образовавшихся в результате процессов жанровой диффузности. Следует заметить, что А.А. Князев также не разграничивает понятия гибридности и диффузности [Князев, 2002]. Таким образом, в лингвистическом научном дискурсе употребление термина «диффузность» на настоящий момент допускает 
неоднозначную трактовку. Проанализированные варианты использования данного термина как в жанровых исследованиях, так и в работах в области семантики высвечивают различные особенности данного феномена, что обусловливает необходимость обобщения результатов исследований в данном направлении и дальнейшей разработки проблемы с целью уточнения характеристик, границ, проявлений диффузности.

Анализ теоретических изысканий лингвистов и переводоведов по исследованию диффузности и гибридности позволяет провести разграничение данных понятий, основанное на определении границ проявления характеристик того или иного дискурса в рамках жанра. Под гибридностью понимается проявление характеристик разных дискурсов в рамках одного жанра, под диффузностью понимается размытость характеристик вследствие взаимодействия разных дискурсов и переплетения их воедино в новой органичной форме. Таким образом, гибридность предполагает наличие характеристик, которые можно соотнести с одним из жанров или дискурсов, образующим гибрид. Диффузность заключается в наличии характеристик, не соотносимых с конкретным дискурсом или жанром, то есть они могут обладать чертами нескольких жанров или дискурсов, представляя собой новые явления. Отметим, что в рамках одного жанра и одного текста может быть выявлена как гибридность, так и диффузность.

Приведем пример, демонстрирующий проявление диффузности в тексте жанра аналитической статьи по юриспруденции.

(3) The Hungarian government, which in the decade since Orbán took over has been accused of rolling back freedoms and democratic norms, has insisted that its measures are purely about fighting the coronavirus, and Orbán's spokesman has dismissed criticism of them as "fake news" (Walker Sh.).

Венгерское правительство (...) настаивает на том, что его меры направлены исключительно на борьбу с коронавирусом, а официальный представитель Орбана отверг критику в адрес этих мер как «фейковые новости» (InoPressa).

В приведенном фрагменте использовано словосочетание fake news, представляющее собой неологизм, который вошел в юридический дискурс из медийного и политического дискурсов, и в настоящее время не представляется возможным четко характеризовать его как элемент одного из названных дискурсов. То же можно сказать и о русскоязычном эквиваленте фейковые новости. Перевод не вызывает трудностей, прагматика оригинала соблюдается благодаря использованию эквивалента. Принадлежащее нескольким дискурсам и достаточно частотно употребляющееся словосочетание фейковые новости не является пока общеупотребительным, в нем сохраняется принадлежность специальному дискурсу. При его рассмотрении в тексте жанра аналитической статьи по юриспруденции мы не можем определить его как элемент, принадлежащий либо медийному, либо юридическому дискурсу - он принадлежит и тому, и другому, что можно считать результатом диффузности.

(4) Private sector tech firms, accountants and lawyers will be drafted in to help the government combat "high-end money laundering" in an acknowledgement that the state does not have the resources to hunt down crime bosses alone (Shipman T.).

«ИТ-фирмы из частного сектора, бухгалтеров и юристов привлекут к борьбе правительства со “сверхсовременным отмыванием денег”; так признается тот факт, что у государства не хватает ресурсов для охоты на криминальных авторитетов в одиночку», - говорится в статье (InoPressa).

В примере (4) внимание привлекает словосочетание high-end money laundering (сверхсовременное отмывание денег). Термин money laundering имеет юридический статус, как и его русскоязычный эквивалент отмывание денежных средств. Понятие возникло в США в 30-х гг. ХХ в., когда американские преступники легализовывали полученные незаконным путем денежные средства с помощью системы прачечных, по аналогии «отмывали» [Туранин, 2018, с. 117]. Прежде чем словосочетание отмывание денежных средств вошло в русскоязычный юридический дискурс и законодательные тексты, оно использовалось в медийном дискурсе. Имея законодательное закрепление, данный термин все же обладает определенным стилистическим «фоном», вероятно, из-за метафорического компонента в его основе. Учитывая историю происхождения и распространения термина, а 
также тот факт, что, будучи элементом юридической терминологии, словосочетание еще не утратило некую стилистическую окрашенность, можно сделать вывод о диффузности рассматриваемого компонента. Компонент high-end (сверхсовременный) из двух взаимодействующих дискурсов характерен для медийного и, таким образом, с точки зрения гибридности дискурсов, может квалифицироваться как компонент, привнесенный медийным дискурсом. Рассмотренный пример демонстрирует реализацию гибридности и диффузности в тексте одной аналитической статьи по юриспруденции.

(5) EU to use Magnitsky-style law to impose sanctions on human rights abusers (Boffey D.).

The Guardian (Великобритания): ЕС введет санкции против нарушителей прав человека, используя юридические нормы типа закона Магнитского (ИноСМИ.RU).

Употребленное в примере (5) словосочетание Magnitsky-style law образовано соединением юридического термина Magnitsky law и компонента -style. Словосочетание изначально использовалось в текстах медийного дискурса, однако оно представлено и в юридическом дискурсе: Globally the human rights regime is changing and for an increasing number of Western governments, Magnitsky-style laws are a useful tool (Submission to the Australian...), что позволяет характеризовать Magnitsky-style law как элемент, создающий диффузность дискурса. При передаче единицы перевода на русский язык (юридические нормы типа закона Магнитского - ИноСМИ.RU) не удалось избежать стилистических потерь, однако с точки зрения содержательной составляющей перевод вполне эксплицирован для реципиента с достаточной для чтения юридической медийной аналитики пресуппозицией.

В переводе диффузность может стать причиной смысловых потерь. Обратим внимание на сложности перевода англоязычного термина lawfare, используемого немецким экспертом по международному праву:

(6) Kurz gesagt, „Kosovo” ist zu einer Chiffre für verschiedene Formen von "lawfare” Kriegsführung mit den Mitteln des Rechts - geworden.
Der Bezug auf „Kosovo” steht auch dafür, dass Recht und Politik selten getrennt voneinander betrachtet werden können (Die Krim - ist das Völkerrecht...).

Иными словами, Косово стало своего рода кодовым словом для различных форм «правовой войны». Ссылка на Косово означает также тот факт, что политика и право лишь в редких случаях могут рассматриваться отдельно друг от друга (Пригодно ли международное право...).

Термин lawfare в исходном тексте дан с разъяснением в постпозиции (Kriegsführung mit den Mitteln des Rechts), которое представляет собой свернутую дефиницию для специалистов, знакомых с историей возникновения и узусом данного термина. Его перевод как правовая война не совсем корректен: термин образован по аналогии с warfare (боевые действия), и буквальный перевод правовые действия тоже нельзя считать удачным, потому что lawfare - это использование международного права в качестве средства достижения военных целей, то есть фактически боевые действия под прикрытием международного права. Мы наблюдаем диффузный, почти «инфекционный» характер переноса компактной терминологической единицы в контент медиаплатформы, и последствия неправомерности «сворачивания» номинации таковы, что могут вызвать сомнения в компетентности эксперта или переводчика у компетентной аудитории данного онлайн-проекта.

Рассмотренные примеры демонстрируют сложность разграничения понятий диффузности и гибридности в рамках изучения жанров, что указывает на перспективу дальнейшей разработки проблемы. Для более полного представления о взаимодействии дискурсов в рамках жанров медийной аналитики следует также рассмотреть свойство интертекстуальности, на проявление которой оказывает влияние взаимодействие базового и проективного дискурсов.

\section{Интертекстуальность в медийной аналитике}

Интертекстуальность является основной текстопорождающей и смыслообразующей категорией, отражающей диалогическое взаимодействие текстов в плане содержания и выражения, осуществляемого как на уровне 
B.А. Митягина, Ю.В. Чеметева. Перевод аналитической статьи для массмедиа: прагматика дискурсов

текстового целого, так и отдельных смысловых и формальных элементов [Безруков, 2015, с. 70]. В медийном дискурсе, как наиболее динамичном, развивающемся, демократичном, формы проявления интертекстуальности практически не ограничены. В юридическом дискурсе в «чистом виде» интертекстуальность проявляется в отсылке к различным нормативным правовым актам, документам, решениям суда, прецедентам, положениям юридической доктрины и т. д.

При взаимодействии юридического дискурса с медийным в рамках жанра аналитической статьи по юриспруденции интертекстуальность приобретает новые формы, при этом ее функциональность главным образом обусловлена прагматическими факторами. Если в тексте юридического дискурса при отсылке на определенные законодательные меры приводятся ссылки на нормативные правовые акты, фиксирующие данные меры, то при упоминании тех же мер в тексте медийного дискурса ссылки даются на тексты (зачастую также медийного дискурса), в которых описано действие и сущность данных мер. Приведем примеры (рис. 1 и 2).

В тексте оригинала (рис. 1 - Walker Sh.) имеется отсылка $a$ set of measures introduced on Monday, оформленная в виде гиперссылки и выделенная цветом и подчеркиванием. При переводе (рис. 2 - InoPressa) полностью сохраняется смысл оригинала, однако графическая составляющая (подчеркивание, цвет текста) теряется, а связь с текстом, на который ссылается оригинал и к которому ведет гиперссылка, разрывается.

Наиболее распространенной формой интертекстуальности в медийной аналитике является цитирование. Приведем пример:

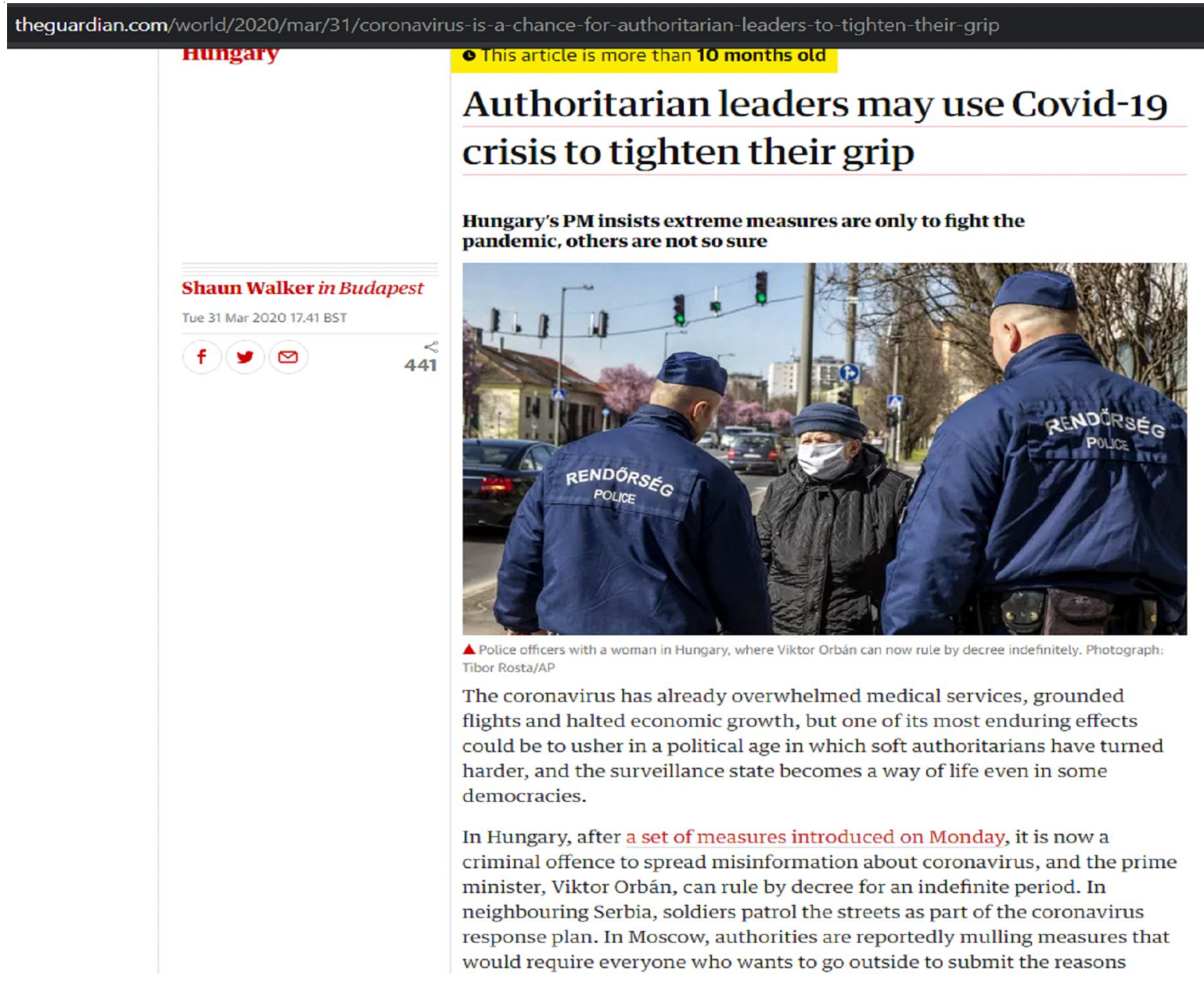

Рис. 1. Интертекстуальность, выраженная гиперссылкой в тексте аналитической статьи по юриспруденции Fig. 1. Intertextuality expressed as a hyperlink in the text of an analytical article on legal issues 
(7) Ivan Krastev, a Bulgarian political scientist who has written extensively on European political shifts, referred to the Hungarian law as "a kind of authoritarian entrepreneurship", comparing it to people selling masks and other equipment at inflated prices (Walker Sh.).

Иван Крастев, болгарский политолог, который много писал о европейских политических сдвигах, назвал венгерский закон «своего рода авторитарным предпринимательством», сравнивая его с людьми, продающими маски и другое оборудование по завышенным ценам (InoPressa).

При переводе цитат важнейшим аспектом является смысловая составляющая фразы, и главной переводческой задачей - точность ее передачи. Пример (7) демонстрирует успешное решение данной задачи: a kind of authoritarian entrepreneurship - своего рода авторитарным предпринимательством.

Помимо эксплицитных форм интертекстуальности, медийные тексты аналитических жанров могут содержать имплицитные формы. Приведем фрагмент аналитической статьи по юриспруденции, содержащий аллюзию:

(8) Meanwhile, in the UK the government seems more intent on discussing Scotch eggs and preventing the playing of Christmas board games than stopping a Russian takeover of the Arctic (Pike F.).
Между тем в Соединенном Королевстве правительству, по всей видимости, интереснее обсуждать яйца по-шотландски и то, как помешать людям играть в настольные игры в Рождество, нежели меры по предотвращению захвата Арктики Россией (ИноСМИ.RU).

Фpaza discussing Scotch eggs and preventing the playing of Christmas board games отсылает к дискуссии, возникшей в Великобритании в ответ на ограничения второго уровня, направленные на сдерживание распространения COVID-19 и позволяющие пабам подавать алкоголь только вместе с основным блюдом. Объем понятия «основного блюда» обсуждался на высшем уровне, вызвав возмущение предпринимателей и граждан. В приведенном фрагменте речь идет также об ограничениях, распространяющихся на время рождественских праздников. Правительство обсуждало разумность послабления ограничений и разрешения собираться дома одновременно трем семьям с 23 по 27 декабря с оговоркой, что люди должны помнить о вероятности заражения коронавирусом.

В тексте оригинала аллюзия в силу резонансного характера темы распознаваема для потенциального реципиента, чем обусловлено отсутствие ссылки на текст, освещающий прецедент. Однако для русскоязычной аудитории интерпретация аллюзии сопряжена

Авторитарные лидеры могут использовать кризис, связанный с Covid-19, для укрепления своей власти

"Коронавирус уже создал чрезмерное давление на медицинские службы, посадил на землю самолеты и остановил экономический рост, но одним из его наиболее устойчивых последствий может стать вступление в политическую эпоху, когда мягкие авторитарные деятели становятся жестче, а полицейское государство становится образом жизни даже в некоторых демократиях", - пишет The Guardian.

"В Венгрии, после ряда мер, введенных в понедельник, распространение дезинформации о коронавирусе объявлено уголовным преступлением, и премьер-министр Виктор Орбан может править с помощью указов в течение неопредепенного периода времени. В соседней Сербии солдаты патрулируют улицы в рамках плана реагирования на коронавирус. В Москве власти, как сообщается, обдумывают меры, которые потребуют от всех, кто хочет выйти на улицу, сообщить причины онлайн, а затем за ними будут следить по телесрону", - говорится в статье.

Рис. 2. Реализация интертекстуального элемента в переводе текста аналитической статьи по юриспруденции

Fig. 2. Intertextual element in the translated text of an analytical article on legal issues 
B.А. Митягина, Ю.В. Чеметева. Перевод аналитической статьи для массмедиа: прагматика дискурсов

с трудностями. Отсутствие экспликации значения лексической единицы в тексте перевода объясняется стилистическими причинами, однако возможности медийного дискурса позволяют дать пояснение для интересующегося реципиента путем добавления в текст гиперссылки на другой текст, более подробно освещающий затронутую в аллюзии тему - и эта прагматическая задача перевода была бы успешно решена.

Приведенные примеры демонстрируют различные проявления интертекстуальности в жанре аналитической статьи по юриспруденции. При переводе рассмотренных фрагментов решающим фактором выступает прагматика дискурсов, обусловливающая проявление данной характеристики.

\section{Выводы}

Жанры медийной аналитики представляют собой продукт взаимодействия базового (медийного) и проективных (юридического, научного, политического, медицинского, экономического и т. д.) дискурсов. Медийный дискурс «форматирует» основные прагматические характеристики в рамках жанра и адаптирует к нему параметры проективных дискурсов. Перевод таких текстов, в частности, текстов аналитических массмедийных статей по юриспруденции, сопряжен с необходимостью учитывать гибридность, диффузность и интертекстуальность этого жанра.

Данные характеристики актуализируют такие компетенции переводчика, как знание терминологии базового и проективного дискурсов на языке оригинала и языке перевода, осведомленность в номинативных процессах, прежде всего, дискурсивно детерминированной неологизации в пространствах заданных языков. Наряду с этим востребованными становятся умения переводчика проводить стилистические преобразования, с помощью которых возможно преодолеть различия тональностей дискурсов. В целом тексты медийной аналитики представляют собой один из самых сложных объектов перевода, поскольку дискурсивная и жанровая комбинаторика требует от переводчика максимально высокого уровня компетентности.

\section{ПРИМЕЧАНИЕ}

${ }^{1}$ Исследование выполнено при финансовой поддержке РФФИ в рамках научного проекта № 20-312-90026 «Юридическая аналитика в пространстве медийного дискурса».

The reported study was funded by RFBR, project number 20-312-90026 "Legal analytics in the media discourse space".

\section{СПИСОК ЛИТЕРАТУРЫ}

Багдасарян О. Ю., Еремина С. А., 2010. «Игра в классики»: современная культурная ситуация // Филологический класс. № 24. С. 42-43.

Безруков А. Н., 2015. Рецепция художественного текста: функциональный подход. Вроцлав : Русско-польский институт. $300 \mathrm{c}$.

Борисова С. С., 2015. Реализация персуазивных стратегий в аналитическом жанре «передовая статья» (Leitartikel) как ресурс информационного доминирования// Научный вестник Воронежского государственного архитектурностроительного университета. Серия: Современные лингвистические и методико-дидактические исследования. № 1 (25). С. 102-114.

Букеева М. Е., 2014. Гибридность и ее проявления в немецкоязычном презентационном дискурсе (на примере информационно-рекламных материалов) // Филологические науки. Вопросы теории и практики. № 4-2 (34). С. 58-62.

Быкова О. И., 2013. Десятый съезд российского союза германистов // Вестник ВГУ. Серия: Лингвистика и межкультурная коммуникация. № 1. C. 235-237.

Войтишенюк Е. В., 2014. Особенности структурной организации диффузной жанровой модели «очерк-рекомендация» (на материале англоязычной и белорусскоязычной прессы) // Известия Гомельского государственного университета им. Ф. Скорины. № 1 (82). С. 54-58.

Войтишенюк Е. В., 2015. Особенности структуры диффузного жанра «телеблог» в белорусскоязычном медийном дискурсе // Беларусь в современном мире : материалы VIII Междунар. науч. конф. студентов, аспирантов и молодых ученых, Гомель, 5 мая 2015 г. / под общ. ред. В. В. Кириенко. Гомель : Изд-во ГГТУ им. П. О. Сухого. С. 191-194.

Ганеев Б. Т., 2003. Первоначальная энантиосемия и диффузность в языке // Вестник Оренбургского государственного университета. № 4. С. 9-14.

Градюшко А. А., 2015. Гибридные жанровые формы в современной интернет-журналистике // Век информации. №3. С. 156-158. 
Исаков В. Б., 2018. Право на аналитику // Гражданин. Выборы. Власть. № 4. С. 116-135.

Кисткина Ю. М., 2017. Гибридность в романе Нила Геймана «Американские боги» и его переводе на русский язык // Лингвокультурология : ежегод. сб. науч. тр. Екатеринбург. Вып. 11. С. 58-78.

Князев А. А., 2002. Аналитическая журналистика // Энциклопедический словарь CMИ. URL: http://ponjatija.ru/node/14654 (дата обращения: 17.12.2020).

Кройчик Л. Е., 2014. Принципы публицистического творчества // Вестник Московского университета. Серия 10, Журналистика. № 5. С. 130 144.

Малышева Е. Г., Гриднев Н. А., 2015. Специфика гибридных жанров в журналистике (на материале публицистических текстов омского журналиста С.Н. Шкаева) // Коммуникативные исследования. № 4 (6). С. 111-122.

Митягина В. А., 2015. Гибридность дискурса как фактор развития коммуникации // Научное наследие академика В.И. Борковского и современная русская словесность : материалы Междунар. науч. конф. Волгоград : Изд-во ВолГУ. С. 290-296.

Новикова Т. Б., 2017а. Гибридный массмедийный дискурс как переводческая проблема // Ноmо Loquens : (Вопросы лингвистики и транслятологии) : сб. ст. / отв. ред. В.А. Митягина [и др.]. Волгоград : Изд-во ВолГУ. Вып. 10. C. $95-102$.

Новикова Э. Ю., 2017б. Дискурсивная личность переводчика: переводческие компетенции и ролевой портрет // Вестник Волгоградского государственного университета. Серия 2, Языкознание. Т. 16, № 3. C. 90-102. DOI: https:// doi.org/10.15688/jvolsu2.2017.3.9.

Пастухов А. Г., 2020. Медиажанры и композиционно-речевые формы журналистики: связи и отношения // Вестник Кемеровского государственного университета. Т. 22, № 4. С. $1107-$ 1115. DOI: https://doi.org/10.21603/2078-89752020-22-4-1107-1115.

Романова С. В., 2018. Жанровые тенденции в русскоязычной прозе Беларуси конца XX - начала XXI веков // Вестник Полоцкого государственного университета. Серия А. Гуманитарные науки. Литературоведение. № 10. C. 20-24.

Сладкевич Ж. Р., 2016. Организация семиотического пространства новогоднего поздравления президента (на материале новогодних обращений президентов России, Беларуси и Польши за 2000-2015 гг.) // Политическая наука. № 3 (2). С. 168-193.
Сулимов В. А., 2010. Персона как фантом: литературный текст и Кризис идентичности // Вестник МАН РС. № 1. С. 53-58.

Тертычный А. А., 2013. Форматирование жанров в периодических печатных средствах массовой информации в России // Российский гуманитарный журнал. Т. 2, № 2. С. 117-130.

Туранин В. Ю., 2018. Феномен юридической терминологии / под ред. Н. А. Власенко. М. : Юрлитинформ. 184 с.

Флджян Л. Г., 2014. О жанровых особенностях англоязычного виртуального газетного дискурса // Научно-исследовательский центр русской филологии и культуры Хэйлунцзянского университета. URL: http://rlls.hlju.edu.cn/eyu_ru/ content_view.asp?id=1567 (дата обращения: 17.12.2020).

Химик В. В., 2011. Диффузное варьирование слов, значений и формантов в русской разговорно-обиходной речи // Вестник Нижегородского университета им. Н. И. Лобачевского. № 6. C. 717-720.

Хотног А. В., 2019. Природа гибридного дискурса (на материале французского языка) // Филологические науки. Вопросы теории и практики. № 8. С. 190-194.

Шевченко Л. И., 2014. Аналитические медиажанры в пространстве времени и языка // Медиалингвистика. Вып. 3. Речевые жанры в массмедиа : сб. ст. СПб. : Изд-во С.-Петерб. гос. унта : Ин-т «Высш. шк. журн. и масс.коммуникаций». С. 48-51.

Шмелев Д. Н., 1990. Полисемия // Лингвистический энциклопедический словарь / гл. ред. В. Н. Ярцева. М. : Сов. энцикл. URL: http://tapemark. narod.ru/les/index.html (дата обращения: 10.12.2020).

Heinemann M., Heinemann W., 2002. Grundlagen der Textlinguistik. Interaktion - Text - Diskurs. Tübingen : Niemeyer. $294 \mathrm{~S}$.

Pym A., 2005. Against Praise of Hybridity // Across Languages and Cultures. A Multidisciplinary Journal for Translation and Interpreting Studies. Vol. 2 (2). P. 195-206.

Schäffner Ch., Adab B., 2005. The Idea of the Hybrid Text in Translation: Contact as Conflict // Across Languages and Cultures. A Multidisciplinary Journal for Translation and Interpreting Studies. Vol. 2 (2). P. 167-180.

Simon Sh., 2005. Cultural and Textual Hybridity // Across Languages and Cultures. A Multidisciplinary Journal for Translation and Interpreting Studies. Vol. 2(2). P. 217-226.

Snell-Hornby M., 2005. The Space 'In Between': What Is a Hybrid Text? // Across Languages and Cultures. A Multidisciplinary Journal for 
B.A. Митягина, Ю.В. Чеметева. Перевод аналитической статьи для массмедиа: прагматика дискурсов

Translation and Interpreting Studies. Vol. 2 (2). P. 207-216.

Tirkkonen-Condit S., 2001. EU Project Proposals as Hybrid Texts: Observations From a Finnish Research Project // Across Languages and Cultures. A Multidisciplinary Journal for Translation and Interpreting Studies. Vol. 2 (2). P. 261-264.

Zauberga I., 2005. Discourse Interference in Translation // Across Languages and Cultures. A Multidisciplinary Journal for Translation and Interpreting Studies. Vol. 2 (2). P. 265-276.

\section{ИСТОЧНИКИ}

ИноСМИ.RU. URL: https://inosmi.ru (дата обращения: 19.12.2020).

Пригодно ли международное право... - Пригодно ли международное право для решения крымского вопроса? / кол. авт.: К. Бусол, С. Виттке, M. Исаева. URL: https://crimea. dekoder.org/ mezhdunarodnoe-pravo (дата обращения: 25.12.2020).

Archipel Krim: Überblick. URL: https:// crimea.dekoder.org/archipel (date of access: 25.12.2020).

Boffey D. EU to Use Magnitsky-Style Law to Impose Sanctions on Human Rights Abusers // The Guardian. 2020. Nov. 27. URL: https:// www.theguardian.com/world/2020/nov/27/euto-use-magnitsky-style-law-to-imposesanctions-on-human-rights-abusers (date of access: 19.12.2020).

dekoder.org: Читая Европу// https://www.dekoder.org/ ru (дата обращения: 25.12.2020).

dekoder.org: Russland entschlüsseln//https:// www.dekoder.org/de (date of access: 25.12.2020).

Die Krim - ist das Völkerrecht... - Die Krim - ist das Völkerrecht fit genug?/ K. von Busol, M. Issaeva, C. Wittke. URL: https://crimea.dekoder.org/recht (date of access: 25.12.2020).

InoPressa. URL: https://www.inopressa.ru/ (date of access: 20.12.2020).

Pike F. Cold War: Russia's Bid to Control the Arctic // The Spectator. 2020. December 12. URL: https:/ /www.spectator.co.uk/article/cold-war-russiasbid-to-control-the-arctic \#: : text=The $\% 20$ jingoistic\%20Chilingarov $\% 20$ proclaimed $\% 3 \mathrm{~A} \% 20$ 'Our,the $\% 20$ country's $\%$ 20power $\% 20$ and\%20influence (date of access: 19.12.2020).

Shipman T. No 10 Recruits Tech Firms in War Against Organised Crime // The Times, 2018, October 28. URL: https://www.thetimes.co.uk/article/no-10recruits-tech-firms-in-war-against-organisedcrime-kcb60r592 (date of access: 10.12.2020).
Submission to the Australian Parliamentary Joint Standing Committee on Foreign Affairs, Defence and Trade. 2020, February 17. URL: https://www.hrw.org/ news/2020/02/17/submission-australianparliamentary-joint-standing-committee-foreignaffairs (date of access: 10.12.2020).

Talmon S. Pflicht zum Ärgern // https://www.jura.unibonn.de/fileadmin/F a chberei ch Rechtswissenschaft/Einrichtungen/Institute/ Voelkerrecht/Dokumente_fuer_Webseite/ FAZ 3.4.2014_S.8_Pflicht_zum_AErgern.pdf(date of access: 26.12 .2020 ).

Walker Sh. Authoritarian Leaders May Use Covid19 Crisis to Tighten Their Grip // The Guardian. 2020, 31 Mar. URL: https:// www.theguardian.com/world/2020/mar/31/ coronavirus-is-a-chance-for-authoritarianleaders-to-tighten-their-grip (date of access: 10.12.2020).

Weissmann A. Should Trump Be Prosecuted? // The New York Times. 2020. Nov. 24. URL: https:// www.nytimes.com/2020/11/24/opinion/trumpprosecution.html (date of access: 12.12.2020).

\section{REFERENCES}

Bagdasaryan O.Yu., Eremina S.A., 2010. «Igra v klassiki»: sovremennaya kulturnaya situatsiya ["Game in Classics (Hopscotch)": A Modern Cultural Situation]. Filologicheskiy klass [Philological Class], no. 24, pp. 42-43.

Bezrukov A.N., 2015. Retseptsiya khudozhestvennogo teksta: funktsionalnyy podkhod [The Reception of Literary Text: Functional Approach]. Vrotslav, Russko-polskiy institut. 300 p.

Borisova S.S., 2015. Realizacija persuazivnyh strategij v analiticheskom zhanre «peredovaja statja» (Leitartikel) kak resurs informacionnogo dominirovanija [Implementation of Persuasive Strategies in Analytical Genre of Editorial as Resource of Information Dominance]. Nauchnyj vestnik Voronezhskogo gosudarstvennogo arhitekturno-stroitelnogo universiteta. Serija: Sovremennye lingvisticheskie $i$ metodikodidakticheskie issledovanija, no. 1 (25), pp. 102-114.

Bukeeva M.E., 2014. Gibridnost i ee proyavleniya v nemetskoyazychnom prezentatsionnom diskurse (na primere informatsionno-reklamnykh materialov) [Hybridity and Its Manifestations in the German Language Presentation Discourse (By the Example of Information and Advertising Materials)]. Filologicheskie nauki. Voprosy teorii i praktiki [Philology. Theory \& Practice], no. 4-2 (34), pp. 58-62. 
Bykova O.I., 2013. Desyatyy syezd rossiyskogo soyuza germanistov $\left[10^{\text {th }}\right.$ Convention of the Russian Union of German Studies]. Vestnik VGU. Seriya: Lingvistika i mezhkulturnaya kommunikatsiya [Proceedings of Voronezh State University. Series: Linguistics and Intercultural Communication], no. 1, pp. 235-237.

Voytishenyuk E.V., 2014. Osobennosti strukturnoy organizatsii diffuznoy zhanrovoy modeli «ocherk-rekomendatsiya» (na materiale angloyazychnoy i belorusskoyazychnoy pressy) [Features of the Structural Organization of the Diffuse Genre Model "EssayRecommendation" (Based on the English and Belarusian-Press)]. Izvestiya Gomelskogo gosudarstvennogo universiteta im. F. Skoriny [Francisk Scorina Gomel State University Proceedings], no. 1 (82), pp. 54-58.

Voytishenyuk E.V., 2015. Osobennosti struktury diffuznogo zhanra «teleblog» v belorusskoyazychnom mediynom diskurse [Features of the Structure of the Diffuse Genre "Teleblog" in the Belarusian-Language Media Discourse]. Kirienko V.V., ed. Belarus v sovremennom mire: materialy VIII Mezhdunar. nauch. konf. studentov, aspirantov $i$ molodykh uchenykh, Gomel, 5 maya $2015 \mathrm{~g}$. [Belarus in the Modern World. Proceedings of the $8^{\text {th }}$ International Scientific Conference of Students, Postgraduate Students and Young Scientists, Gomel, May 5, 2015]. Gomel, Izd-vo GGTU im. P.O. Sukhogo, pp. 191-194.

Ganeev B.T., 2003. Pervonachalnaya enantiosemiya i diffuznost v yazyke [Primary Enantiosemy and Diffuseness in a Language]. Vestnik Orenburgskogo gosudarstvennogo universiteta [Vestnik of the Orenburg State University], no. 4, pp. 9-14.

Gradyushko A.A., 2015. Gibridnye zhanrovye formy v sovremennoy internet-zhurnalistike [Hybrid Genre Forms in Modern Online Journalism]. Vek informatsii [Information Age], no. 3, pp. 156-158.

Isakov V.B., 2018. Pravo na analitiku [The Right to of Analytics]. Grazhdanin. Vybory. Vlast [Citizen. Elections. Authority], no. 4, pp. 116-135.

Kistkina Yu.M., 2017. Gibridnost v romane Nila Geymana «Amerikanskie bogi» i ego perevode na russkiy yazyk [Hybridity in the Novel "American Gods" by Neil Gaiman and Its Russian Translation]. Lingvokulturologiya: ezhegod. sb. nauch. tr. [Linguoculturology. Annual Collection of Scientific Papers]. Yekaterinburg, iss. 11, pp. 58-78.

Knyazev A.A., 2002. Analiticheskaya zhurnalistika [Analytical Journalism]. Entsiklopedicheskiy slovar SMI [Encyclopedic Dictionary of Mass
Media]. URL: http://ponjatija.ru/node/14654 (accessed 17 December 2020).

Kroychik L.E., 2014. Printsipy publitsisticheskogo tvorchestva [The Principles of Publicistic Writing]. Vestnik Moskovskogo universiteta. Seriya 10, Zhurnalistika, no. 5, pp. 130-144.

Malysheva E.G., Gridnev N.A., 2015. Spetsifika gibridnykh zhanrovv zhurnalistike (na materiale publitsisticheskikh tekstov omskogo zhurnalista S.N. Shkaeva) [Specifics of Hybrid Genres in Journalism (On the Basis of Journalistic Texts of Omsk Journalist Shkaev S.N.)]. Kommunikativnye issledovaniya [Communication Studies], no. 4(6), pp. 111-122.

Mityagina V.A., 2015. Gibridnost diskursa kak faktor razvitiya kommunikatsii [Discourse Hybridity as a Factor of Communication Development]. Nauchnoe nasledie akademika V.I. Borkovskogo i sovremennaya russkaya slovesnost: materialy Mezhdunar. nauch. konf. [Scientific Heritage of Academician V.I. Borkovsky and Modern Russian Literature. Proceedings of the International Scientific Conference]. Volgograd, Izd-vo VolGU, pp. 290-296.

Novikova T.B., 2017a. Gibridnyy massmediynyy diskurs kak perevodcheskaya problema [Hybrid Mass Media Discourse as the Problem of Translation]. Mityagina V.A. et al., eds. Homo Loquens: (Voprosy lingvistiki i translyatologii): sb. st. [Homo Loquens (Issues of Linguistics and Translatology). Collected Articles]. Volgograd, Izd-vo VolGU, iss. 10, pp. 95-102.

Novikova E.Yu., 2017b. Diskursivnaya lichnost perevodchika: perevodcheskie kompetentsii i rolevoy portret [Discursive Personality of the Translator: Translation Competencies and Role Portrait]. Vestnik Volgogradskogo gosudarstvennogo universiteta. Seriya 2, Yazykoznanie [Science Journal of Volgograd State University. Linguistics], vol. 16, no. 3, pp. 90-102. DOI: https://doi.org/10.15688/ jvolsu2.2017.3.9.

Pastukhov A.G., 2020. Mediazhanry i kompozitsionnorechevye formy zhurnalistiki: cvyazi i otnosheniya [Media Genres and Compositional Speech Forms of Journalism: Relationships and Connections]. Vestnik Kemerovskogo gosudarstvennogo universiteta [Bulletin of Kemerovo State University], vol. 22, no. 4, pp. 1107-1115. DOI: https://doi.org/10.21603/ 2078-8975-2020-22-4-1107-1115.

Romanova S.V., 2018. Zhanrovye tendentsii v russkoyazychnoy proze Belarusi kontsa XX nachala XXI vekov [Genre Tendencies in Russian-Language Prose of Belarus of the Late $20^{\text {th }}-$ Early $21^{\text {th }}$ Centuries]. Vestnik Polotskogo 
B.А. Митягина, Ю.В. Чеметева. Перевод аналитической статьи для массмедиа: прагматика дискурсов

gosudarstvennogo universiteta. Seriya A. Gumanitarnye nauki. Literaturovedenie [Vestnik of Polotsk State University. Part A. Humanities], no. 10, pp. 20-24.

Sladkevich Zh.R., 2016. Organizatsiya semioticheskogo prostranstva novogodnego pozdravleniya prezidenta (na materiale novogodnikh obrashcheniy prezidentov Rossii, Belarusi i Polshi za 2000-2015 gg.) [The Organization of the Semiotic Space of the New Year's President's Greetings (Based on the New Year Messages of the Presidents of Russia, Belarus and Poland in 2000-2015)]. Politicheskaya nauka [Political Science], no. 3 (2), pp. 168-193.

Sulimov V.A., 2010. Persona kak fantom: literaturnyy tekst i Krizis identichnosti [A Person as a Phantom: The Literary Text and Identity Crisis]. Vestnik MAN RS [Herald of the International Academy of Science. Russian Section], no. 1, pp. 53-58.

Tertychnyy A.A., 2013. Formatirovanie zhanrov v periodicheskikh pechatnykh sredstvakh massovoy informatsii $\mathrm{v}$ Rossii [Genre Formatting in Periodic Printed Media of Russia]. Rossiyskiy gumanitarnyy zhurnal [Liberal Arts in Russia], vol. 2, no. 2, pp. 117-130.

Turanin V.Yu., Vlasenko N.A., ed., 2018. Fenomen yuridicheskoy terminologii [Phenomenon of Legal Terminology]. Moscow, Yurlitinform Publ. $184 \mathrm{p}$.

Fldzhyan L.G., 2014. O zhanrovykh osobennostyakh angloyazychnogo virtualnogo gazetnogo diskursa [On Genre Features of the English-Language Virtual Newspaper Discourse]. Nauchnoissledovatelskiy tsentr russkoy filologii i kulury Kheyluntszyanskogo universiteta [Research Center of Russian Philology and Culture of Heilongjiang University]. URL: http:// rlls.hlju.edu.cn/eyu_ru/content_view.asp?id=1567 (accessed 17 December 2020).

Khimik V.V., 2011. Diffuznoe varyirovanie slov, znacheniyi formantov v russkoy razgovorno-obikhodnoy rechi [Diffuse Variation of Words, Meanings, and Formants in the Russian Colloquial Everyday Speech]. Vestnik Nizhegorodskogo universiteta im. N.I. Lobachevskogo [Vestnik of Lobachevsky University of Nizhni Novgorod], no. 6, pp. 717-720.

Khotnog A.V., 2019. Priroda gibridnogo diskursa (na materiale frantsuzskogo yazyka) [Hybrid Discourse Nature (By the Material of the French Language)]. Filologicheskie nauki. Voprosy teorii i praktiki [Philological Sciences. Issues of Theory and Practice], no. 8, pp. 190-194.

Shevchenko L.I., 2014. Analiticheskie mediazhanry v prostranstve vremeni i yazyka [Analytical Media Genres in Space Time and Language].
Medialingvistika. Vyp. 3. Rechevye zhanry $v$ massmedia : sb. st. [Media Linguistics. Issue 3. Speech Genres in Mass Media. Collection of Papers]. Saint Petersburg, Izd-vo SanktPeterburgskogo gosudarstvennogo universiteta: Institut «Vysshaya shkola zhurnalistiki i massovykh kommunikatsiy», pp. 48-51.

Shmelev D.N., 1990. Polisemiya [Polysemy]. Yartseva V.N., ed. Lingvisticheskiy entsiklopedicheskiy slovar [Linguistic Encyclopedic Dictionary]. Moscow, Sovetskaya Entsiklopediya Publ. URL: http://tapemark.narod.ru/les/index.html (accessed 10 December 2020).

Heinemann M., Heinemann W., 2002. Grundlagen der Textlinguistik. Interaktion - Text - Diskurs. Tübingen, Niemeyer. $294 \mathrm{p}$.

Pym A., 2005. Against Praise of Hybridity. Across Languages and Cultures. A Multidisciplinary Journal for Translation and Interpreting Studies, vol. 2 (2), pp. 195-206.

Schaffner Ch., Adab B., 2005. The Idea of the Hybrid Text in Translation: Contact as Conflict. Across Languages and Cultures. A Multidisciplinary Journal for Translation and Interpreting Studies, vol. 2 (2), pp. 167-180.

Simon Sh., 2005. Cultural and Textual Hybridity. Across Languages and Cultures. A Multidisciplinary Journal for Translation and Interpreting Studies, vol. 2 (2), pp. 217-226.

Snell-Hornby M., 2005. The Space 'In Between': What is a Hybrid Text? Across Languages and Cultures. A Multidisciplinary Journal for Translation and Interpreting Studies, vol. 2 (2), pp. 207-216.

Tirkkonen-Condit S., 2001. EU Project Proposals as Hybrid Texts: Observations From a Finnish Research Project. Across Languages and Cultures. A Multidisciplinary Journal for Translation and Interpreting Studies, vol. 2 (2), pp. 261-264.

Zauberga I., 2005. Discourse Interference in Translation. Across Languages and Cultures. A Multidisciplinary Journal for Translation and Interpreting Studies, vol. 2 (2), pp. 265-276.

\section{SOURCES}

InoSMI.RU. URL: https://inosmi.ru (accessed 19 December 2020).

Busol K., Vittke S., Isayeva M. Prigodno li mezhdunarodnoye pravo dlya resheniya krymskogo voprosa? [Is International Law Suitable for the Settlement of the Crimean Dispute?]. URL: https://crimea.dekoder.org/mezhdunarodnoepravo (accessed 25 December 2020). 


\section{ГЛАВНАЯ ТЕМА НОМЕРА}

Archipel Krim: Überblick. URL: https:// crimea.dekoder.org/archipel (accessed 25 December 2020).

Boffey D. EU to Use Magnitsky-Style Law to Impose Sanctions on Human Rights Abusers. The Guardian, 2020, November 27. URL: https:// www.theguardian.com/world/2020/nov/27/eu-touse-magnitsky-style-law-to-impose-sanctions-onhuman-rights-abusers (accessed 19 December 2020).

dekoder.org: Chitaya Evropu [dekoder.org: Reading Europe]. URL: https://www.dekoder.org/ru (accessed 25 December 2020).

dekoder.org: Russland entschlüsseln. URL: https:// www.dekoder.org/de (accessed 25 December 2020).

Busol K. von, Issaeva M., Wittke C. Die Krim - ist das Völkerrecht fit genug? URL: https:// crimea.dekoder.org/recht (accessed 25 December 2020).

InoPressa. URL: https://www.inopressa.ru (accessed 20 December 2020).

Pike F. Cold War: Russia's Bid to Control the Arctic. The Spectator, 2020, December 12. URL: https:/ /www.spectator.co.uk/article/cold-war-russiasbid-to-control-the-arctic $\#: \sim$ :text $=$ The $\% 20$ jingoistic $\% 20$ Chilingarov $\% 20$ proclaimed $\% 3 \mathrm{~A}$ $\% 20$ 'Our,the $\% 20$ country's $\% 20$ power $\% 20$ and $\% 20$ influence (accessed 19 December 2020).
Shipman T. No 10 Recruits Tech Firms in War Against Organised Crime. The Times, 2018, October 28. URL: https://www.thetimes.co.uk/article/no-10recruits-tech-firms-in-war-against-organisedcrime-kcb60r592 (accessed 10 December 2020).

Submission to the Australian Parliamentary Joint Standing Committee on Foreign Affairs, Defence and Trade, 2020, February 17. URL: https://www.hrw.org/news/2020/02/17/ submission-australian-parliamentary-jointstanding-committee-foreign-affairs (accessed 10 December 2020).

Talmon S. Pflicht zum Ärgern. URL: https:// www.jura.uni-bonn.de/fileadmin/Fachbereich Rechtswissenschaft/Einrichtungen/Institute/ Voelkerrecht/Dokumente fuer_Webseite/ FAZ_3.4.2014_S.8_Pflicht_zum_ĀErgern.pdf (accessed 26 December 2020).

Walker Sh. Authoritarian Leaders May Use Covid-19 Crisis to Tighten Their Grip. The Guardian, 2020, March 31. URL: https://www.theguardian.com/ world/2020/mar/31/coronavirus-is-a-chance-forauthoritarian-leaders-to-tighten-their-grip (accessed 10 December 2020).

Weissmann A. Should Trump Be Prosecuted? The New York Times, 2020, November 24. URL: https:// www.nytimes.com/2020/11/24/opinion/trumpprosecution.html (accessed 12 December 2020).

\section{Information About the Authors}

Vera A. Mityagina, Doctor of Sciences (Philology), Professor, Head of the Department of Translation Theory and Practice, Volgograd State University, Prosp. Universitetsky, 100, 400062 Volgograd, Russia,mityagina@mail.ru, https://orcid.org/0000-0002-3997-3139

Yuliya V. Chemeteva, Postgraduate Student, Assistant Lecturer, Department of Translation Theory and Practice, Volgograd State University, Prosp. Universitetsky, 100, 400062 Volgograd, Russia, chemeteva@volsu.ru, https://orcid.org/0000-0002-9134-5789

\section{Информация об авторах}

Вера Александровна Митягина, доктор филологических наук, профессор, заведующий кафедрой теории и практики перевода, Волгоградский государственный университет, просп. Университетский, 100, 400062 г. Волгоград, Россия, mityagina@mail.ru, https://orcid.org/0000-0002-3997-3139

Юлия Владимировна Чеметева, аспирант, ассистент кафедры теории и практики перевода, Волгоградский государственный университет, просп. Университетский, 100, 400062 г. Волгоград, Россия, chemeteva@volsu.ru, https://orcid.org/0000-0002-9134-5789 